\title{
Examination on Tribological Properties of Luffa Fiber Reinforced Polyester Composites
}

\author{
G. Kalusuraman, I. Siva
}

\begin{abstract}
In this work Tribological property of luffa fiber reinforced unsaturated polyester composites are carried out. The composites were fabricated using the compression moulding technique with optimum pressure of 150Mpa. The fabricated specimens were cut as per the ASTM standard of the wear test and ASTM G99 as followed for the entire testing of the wear. In this work, the applying load and velocity of the rotating disc was considered as a process parameter. The fiber loading was taken for the specimen to be fabricated as $30 \%$. The test on the specimen was conducted for $10 \mathrm{~N}, 20 \mathrm{~N}, 30 \mathrm{~N}$ and velocity of $1 \mathrm{~m} / \mathrm{s}, 2 \mathrm{~m} / \mathrm{s}$, $3 \mathrm{~m} / \mathrm{s}$ respectively. The result shows that coefficient of friction increase when increases in sliding distance..
\end{abstract}

Keywords : About four key words or phrases in alphabetical order, separated by commas.

\section{INTRODUCTION}

A composite material is a combination of two or more materials of the different or same property. The composite material is not only used for structural properties, it also considered and detailed in electrical, thermal and mechanical properties. Normally, the natural fibers are used making composites. The advantages of natural fiber composite are easily available, low cost, reasonable strength, stiffness, renewable and biodegradable. luffa fibers are basically available in Thailand. Natural fiber shows little resistance to the environmental influences and intrisnic variability on properties. Kaewta kaewtatip et al reported that they are analyzing the tensile strength of luffa fibers and the details of their chemical structure are studied by the scanning Electron Microscope (SEM) [1]. Valcinide O.A. Tanobe et al. reported that luffa fiber induced in many types of chemical treatments and found their impact properties depend upon chemical products. They are shown that $\mathrm{NaOH}$ treatment is easily improving the surface energy of the fiber [2]. Marissa A. Paglicawan et al. reported that the properties of the luffa fibers only achieve the result of mechanical properties of the composites [3]. Jainhu Shen et al. reported that compared to other fibers the luffa having high strength and stiffness [4]. H. Demir et al. reported that when the luffa is immersed in water it has a water absorption properties in less than 5\% [5]. Irullappasamy Siva et al. reported that Tribological properties of Silane treatment of the coconut and

Revised Manuscript Received on December 5, 2019

* Correspondence Author

G. Kalusuraman*, Faculty of Mechanical Engineering, Kalasalingam Academy of Research and Education, Krishnankoil-626 126, India, Email: kalusunrk@gmail.com

I. Siva , Faculty of Mechanical Engineering, Kalasalingam Academy of Research and Education, Krishnankoil-626 126, India, Email: isiva@klu.com glass fibers are having a less specific wear rate [6]. O. Oboh et al. reported that the luffa is applied on agriculture, biological systems and Research technology [7]. It was observed that many of them conducted reported wear test on sisal, jute, fibers for this article and there is a research gap on wear properties of the luffa composites. In this work, the composites are fabricated with luffa fiber by using the compression molding process. and it is subject to under various loading and different sliding distance.

\section{MATERIALS AND METHODS}

\section{A. Materials used}

The luffa fiber is collected from the location in Natural Herbal shop at virudhunagar. In order to increase the chemical reaction in the resin for the preparation of the composites, catalyst as a methyl ethyl ketone peroxide and accelerator as a cobalt napthenate were used.

\section{B. Fabrication of Composites}

The template Compression moulding machine was used for making a plate of composite materials. The luffa fibers have been prepared and cut into the open book shape then remove the seeds in the fiber. Then selected fiber was used for the treatment process. $30 \%$ of weights of fiber are taking and apply over the top of the plate. Then it is pre-compressed with the help of the compression moulding machine. After the pre-compression, the wax is applied top and bottom side of the plate. Then the pre-compressed fiber was placed on the plate and $70 \%$ of resin was added to the pre-compressed fiber and the plate mould is placed on the compression machine and optimum pressure applied in $50 \mathrm{~kg} / \mathrm{cm} 2$. The curing time for a plate was $12 \mathrm{hrs}$. After $12 \mathrm{hrs}$ the moulds are removed from the machine. Now, the composite was prepared in the size of $180 \times 150 \times 3 \mathrm{~mm} 2$. For the wear testing process, the plate is cut as per standard of ASTM G99 to do wear test.

\section{Testing of Composites}

For the wear testing process, pin on disc wear testing machine was used. According to the condition, the load was taken ad different condition as a $10 \mathrm{~N}, 20 \mathrm{~N}, 30 \mathrm{~N}$. The sliding velocity was as a $1 \mathrm{~m} / \mathrm{s}, 2 \mathrm{~m} / \mathrm{s}, 3 \mathrm{~m} / \mathrm{s}$. The sliding distance was $[0-3000 \mathrm{~m}]$. The wear piece was attached to the rod with the help of glue or pasting compounds. Before wear test, the initial weight of the piece was taken and the work piece was attached to the holder. Then the work piece was placed in a rotating disc and set the time and distance in the machine according to the calculation. The time was set into the machine to depend upon the calculation. The 


\section{Examination on Tribological Properties of Luffa Fiber Reinforced Polyester Composites}

speed and time calculation was done by using the following equation.

$$
\mathrm{V}=3.14 * \mathrm{D} * \mathrm{~N} / 60
$$

Where, v-velocity $(\mathrm{m} / \mathrm{s}), \mathrm{N}$-speed $(\mathrm{rpm}), \mathrm{D}$-Diameter of the $\operatorname{disc}(\mathrm{m})$.

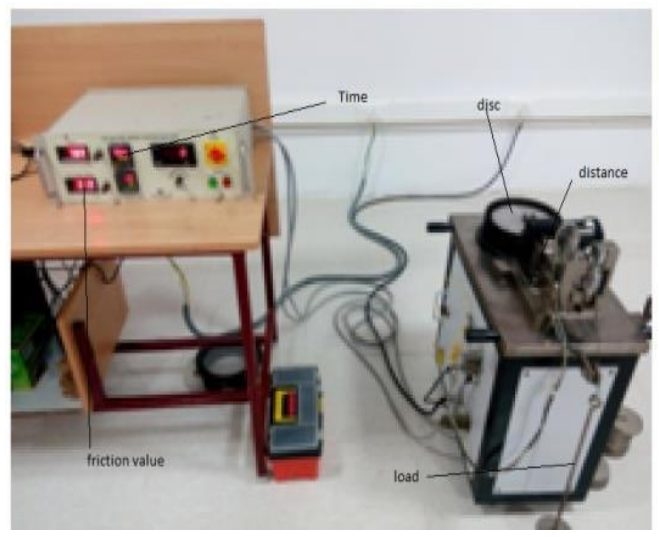

Fig.1. Snap shot of Wear testing machine

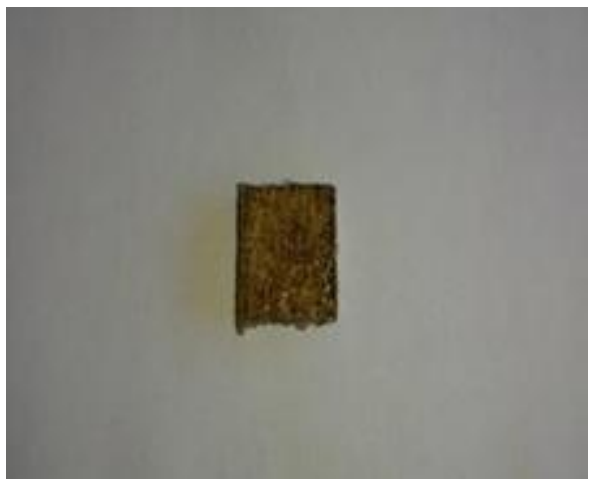

Fig. 2. Photo of Wear piece

III. RESULT AND DISCUSSION

\section{A. Coefficient of friction}

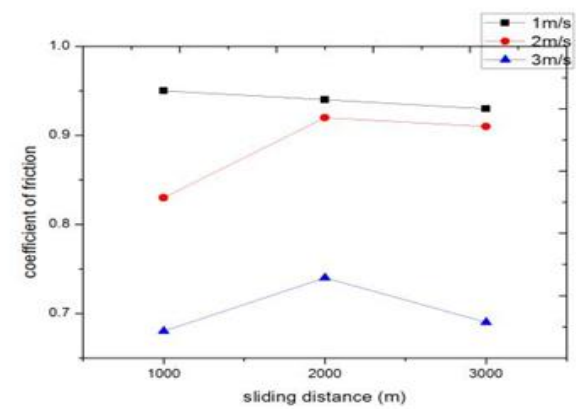

(a)

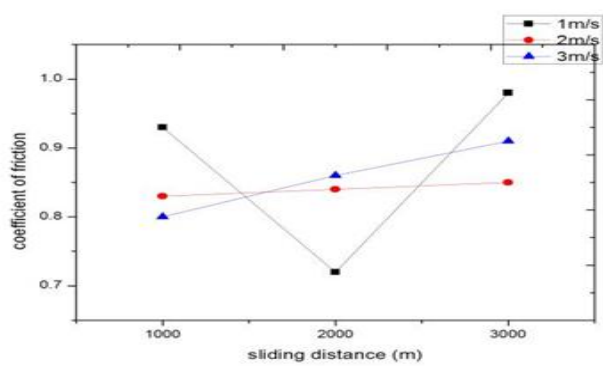

(b)

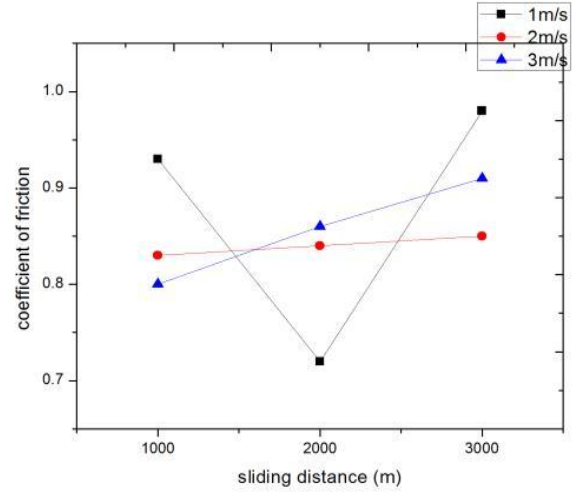

(c)

Fig.3. Effect fiber loading on the coefficient of friction of composites a). $10 \mathrm{~N} \mathrm{~b}) .20 \mathrm{~N} \mathrm{c}) .30 \mathrm{~N}$

For the U30 wear test process in the $10 \mathrm{~N}, 20 \mathrm{~N}, 30 \mathrm{~N}$ load, the coefficient of friction and specific wear rate were calculated and plotted in the graph

The coefficient of friction mainly depends on the load and sliding distance. The above graph was plotted between sliding distance and coefficient of friction. From the graph, it was noted that for testing condition $\mathrm{U} 30$ at $10 \mathrm{~N}$ for $1 \mathrm{~m} / \mathrm{s}$ it has been constantly decreasing. In $2 \mathrm{~m} / \mathrm{s}$, the coefficient of friction is increased up to $2000 \mathrm{~m}$ gradually and it holds steady-state in distance of $3000 \mathrm{~m}$. In $3 \mathrm{~m} / \mathrm{s}$, the sliding distance in $2000 \mathrm{~m}$ it is having a high coefficient of friction. It was observed from the graph(b) that coefficient of friction decreased to 0.7 when the testing condition of $2000 \mathrm{~m}$ and 1 $\mathrm{m} / \mathrm{s}$ since it has the poor interlocking between fiber and matrix. It was observed from the graph(c) that the $1 \mathrm{~m} / \mathrm{s}$ on $2000 \mathrm{~m}$ having a high coefficient of friction. The

$3 \mathrm{~m} / \mathrm{s}$ is sliding increased from $1000 \mathrm{~m}-3000 \mathrm{~m}$.

\section{B. Specific wear rate}

The U30 $10 \mathrm{~N}, 20 \mathrm{~N}, 30 \mathrm{~N}$ specific wear rate graphs are as follows

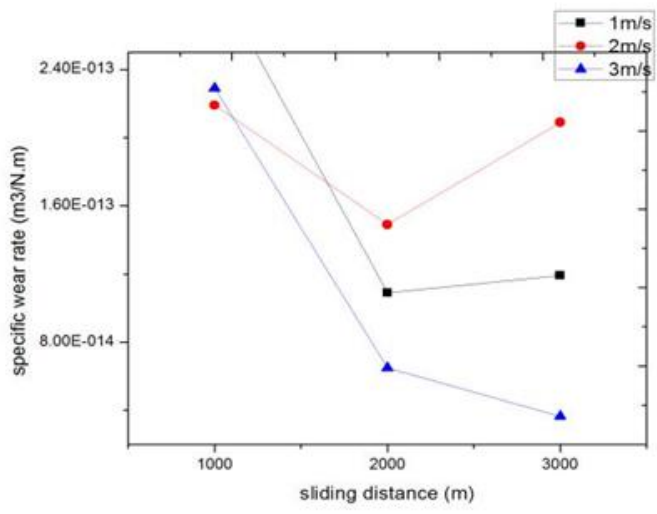

(a) 


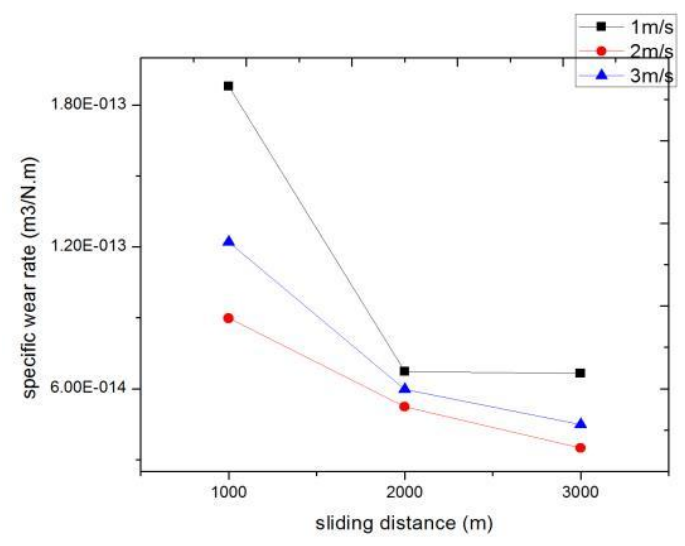

(b)

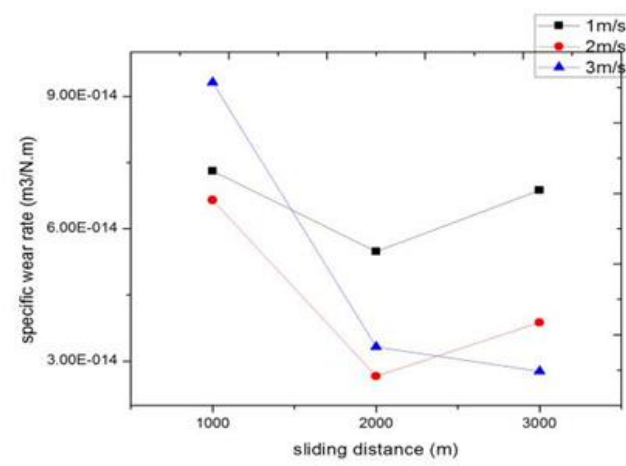

(c)

Fig.4 Effect of fiber loading on the specific wear rate of composites (a). 10N (b). $20 \mathrm{~N}$ (c).30N

\section{Microscopic image.}

The wear surface of specimen microscopic image (Fig 5 ) is shown in the magnification of higher and lower for $30 \mathrm{~N}, 3 \mathrm{~m} / \mathrm{s}$ condition. The figure shows that the worn surface of the fiber and indicates the wear debris

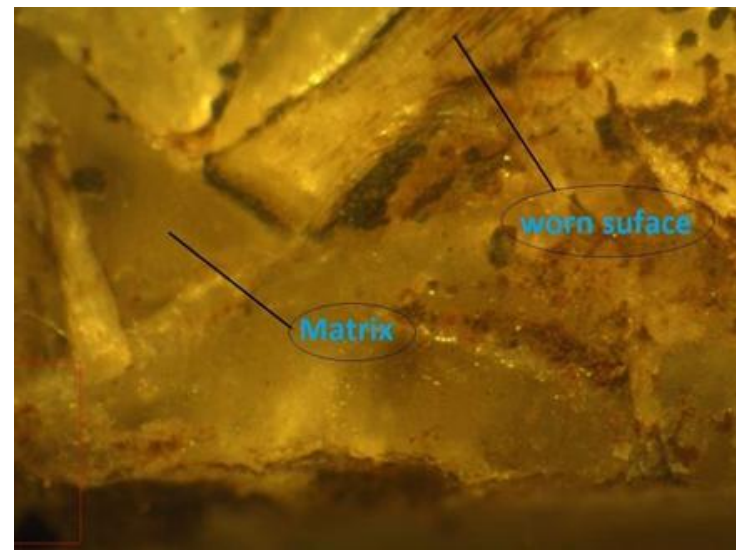

Fig 5. Micropic view of worn sample.

\section{CONCLUSION}

The following conclusions are made a). The composites are made by using the compression moulding technique.

b).In wear test, for the testing condition $30 \mathrm{~N}$ and $3 \mathrm{~m} / \mathrm{s}$, whenever the sliding distance increases the $\mathrm{COF}$ also increased linearly.

\section{REFERENCES}

[1] 1K. Kaewtatip, and J. Thongmee, "Studies on the structure and properties of thermoplastic starch/luffa fiber composites," Materials \& Design, vol. 40, pp.314-318, 2012.

[2] [V. O. Tanobe, T. H. HSydenstricker, M. Munaro, M. and S.C. Amico," A comprehensive characterization of chemically treated Brazilian sponge-gourds (Luffa cylindrica)," Polymer Testing, vol.24, pp.474-482, 2005

[3] M. A. Paglicawan, M. S. Cabillon, R. P. Cerbito, and E. O. Santos, "Loofah fiber as reinforcement material for composite," Philippine Journal of Science, vol. 134, pp.113,2005

[4] J . Shen, Y.M. Xie, X. Huang, S. Zhou and D. Ruan, "Mechanical properties of luffa sponge" Journal of the mechanical behavior of biomedical materials, vol.15, pp.141-152, 2012.

[5] H. Demir, U. Atikler, D. Balköse, and F. Tıhmınlığlu, "The effect of fiber surface treatments on the tensile and water sorption properties of polypropylene-luffa fiber composites," Composites Part A: Applied Science and Manufacturing, vol. 37, pp.447- 456, 2006.

[6] I. Siva, J.T.W Jappes, and B. Suresha," Investigation on mechanical and tribological behavior of naturally woven coconut sheath - reinforced polymer composites" Polymer Composites, vol. 33, pp.723-732, 2012.

[7] O. Oboh and E. O. Aluyor ,"Luffa cylindrica-an emerging cash crop." African Journal of Agricultural Research, vol.4, pp.684-688, 2009.

\section{AUTHORS PROFILE}

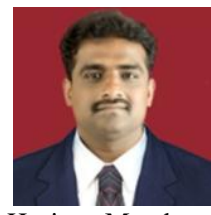

Dr. G. Kalusuraman is currently working as Associate Professor in the Department of Mechanical Engineering, Kalasalingam Academy of Research and Education, Anand nagar, Krishnankoil-626126, India $\mathrm{He}$ has 10 years teaching as well as research experience. He is a reviewer for two reputed journals $\mathrm{He}$ is a Member of Indian Society for Technical Education. His area of interests are polymer composite, materials characterization, tribology.

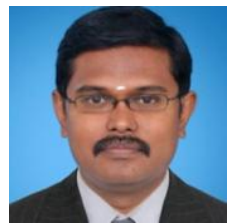

Dr. I. Siva is currently working as Professor in the Department of Mechanical Engineering, Kalasalingam Academy of Research and Education, Anand nagar, Krishnankoil-626126,India He has 15 years teaching as well as research experience. He is a reviewer more than 10 reputed journals $\mathrm{He}$ is a Member of Indian Society for Technical Education .His area of interests are polymer composite, materials characterization, tribology.. 